\title{
EFECTO DE LA HUMEDAD, TEMPERATURA Y PH DEL SUELO EN LA ACTIVIDAD MICROBIANA A NIVEL DE LABORATORIO
}

\section{SOIL MICROBIAL ACTIVITY IN RESPONSE TO DIFFERENT CONDITIONS OF MOISTURE, TEMPERATURE OR PH}

\author{
Elena Ramos ${ }^{1}$ y Doris Zúñiga ${ }^{1}$
}

\begin{abstract}
Resumen
El presente estudio se realizó con la finalidad de evaluar bajo condiciones de laboratorio, la influencia de tres parámetros físico-químicos sobre la actividad microbiana en un suelo agrícola medida por la cuantificación de la producción de $\mathrm{CO}_{2}$ y actividad deshidrogenasa. Se realizaron por separado, tres ensayos para 4 porcentajes de humedad \%(v/p): $5.0 \%, 10.0 \%, 15.0 \%$ y 18.0 \%; 4 temperaturas: $8.0^{\circ} \mathrm{C}, 21.0^{\circ} \mathrm{C}, 27.5^{\circ} \mathrm{C}$ y $37.0{ }^{\circ} \mathrm{C}$; y 4 valores de $\mathrm{pH}: 4.0,6.1,7.8$ y 8.2. Cada ensayo de cuatro tratamientos y 4 repeticiones por tratamiento se condujo siguiendo los lineamientos del diseño completamente al azar (DCA). Los mayores valores de actividad microbiana [0.097 $\mathrm{mg} \mathrm{CO} \cdot$-g-1·h-1 y $173.09 \mu \mathrm{g}$ formazán·g-1·(24h)-1] se obtuvieron a $18 \%$ de humedad, en condiciones estándares de temperatura y $\mathrm{pH}$; se encontró que la temperatura de $27.5^{\circ} \mathrm{C}$ era óptima para producción de $\mathrm{CO}_{2}[0.140 \mathrm{mg} \mathrm{CO} \cdot \mathrm{g}-1 \cdot \mathrm{h}-1]$ y $37.0^{\circ} \mathrm{C}$ para la actividad deshidrogenasa [156.78 $\mu \mathrm{g}$ formazán·g-1·(24h)-1], en condiciones estándares de humedad relativa y pH; y se estableció como $\mathrm{pH}$ óptimo aquel cercano a la neutralidad (7.8) [0.055 mg CO${ }_{2} \cdot \mathrm{g}-1 \cdot \mathrm{h}-1$, $171.19 \mu \mathrm{g}$ formazán·g-1·(24h)-1], en condiciones estándares de humedad relativa y temperatura.

Palabras clave: Actividad microbiana, producción de $\mathrm{CO}_{2}$, actividad deshidrogenasa, humedad, temperatura, $\mathrm{pH}$
\end{abstract}

\begin{abstract}
The aim of this study was to evaluate the influence of three physical-chemical parameters on microbial activity of farm soils under controlled laboratory conditions (18\% humidity, $27.5{ }^{\circ} \mathrm{C}$ and $\mathrm{pH}$ 7.8). Microbial activities were quantified by carbon dioxide production and dehydrogenase activity. Three different essays for 4 moisture percentages (v/w): $5.0 \%, 10.0 \%, 15.0 \%$ and $18.0 \%$, 4 temperatures: $8.0^{\circ} \mathrm{C}, 21.0^{\circ} \mathrm{C}, 27.5^{\circ} \mathrm{C}$ and $37.0{ }^{\circ} \mathrm{C}$, and $4 \mathrm{pH}$ values: $4.0,6.1,7.8$ and 8.2 were evaluated. A Completely Randomized Design (CRD) was used for each essay consisting of four treatments and four replicates per treatment. The highest values on microbial activity [0.097 $\mathrm{mg}$ $\mathrm{CO}_{2} \cdot \mathrm{g}-1 \cdot \mathrm{h}-1$ and $173.09 \mu \mathrm{g}$ formazán.g-1·(24h)-1] were obtained at $18 \%$ humidity. It was found out that a temperature of $27.5^{\circ} \mathrm{C}$ was optimum for carbon dioxide production $\left[0.140 \mathrm{mg} \mathrm{CO}_{2} \cdot \mathrm{g}\right.$ $1 \cdot h-1]$, and $37.0^{\circ} \mathrm{C}$ for dehydrogenase activity [156.78 $\mu$ g formazán.g-1·(24h)-1]. A near to neutral $\mathrm{pH}$ (7.8) was established as optimum [0.055 $\mathrm{mg} \mathrm{CO} \cdot$ ·g-1·h-1and $171.19 \mu \mathrm{g}$ formazán·g-1·(24h)-1]. Key words: Microbial activity, carbon dioxide production, dehydrogenase activity humidity, temperature, $\mathrm{pH}$ value
\end{abstract}

\section{Introducción}

Existen diversos parámetros considerados clave para determinar la calidad del suelo, aquellos de naturaleza física y físico-química (estabilidad de agregados, $\mathrm{pH}$, conductividad eléctrica), química (parámetros nutricionales y fracciones de carbono), como del tipo microbiológico y bioquímico (carbono de biomasa microbiana, respiración microbiana o diversas actividades enzimáticas). El componente microbiológico puede servir como indicador del estado general del suelo, pues una buena actividad microbiana en suelo es reflejo de condiciones físicoquímicas óptimas para el desarrollo de los procesos metabólicos de microorganismos (bacterias, hongos, algas, actinomicetos) que actúan sobre sustratos orgánicos y cultivos asociados; y constituye un marcador biológico potencialmente útil para evaluar las perturbaciones que puedan presentarse. Es muy importante en el desarrollo y funcionamiento de los ecosistemas y su fertilidad, pues interviene tanto en el establecimiento de los ciclos biogeoquímicos, como en la formación de la estructura de los suelos.

Así, las variaciones por unidad de tiempo en la actividad respiratoria pueden ser interpretadas como reflejo de la actividad metabólica de los microorganismos que residen en determinado hábitat y nos da idea de la dinámica de su biota ya que los procesos metabólicos que en él se desarrollan varían 
en función de factores biofísicos, climáticos y del uso de la tierra. Mientras la actividad deshidrogenasa es una medida representativa del metabolismo degradativo de un suelo (Skujins, 1976), puesto que se trata de un tipo de enzima exclusivamente intracelular que por tanto está asociado a células viables, también se considera un buen indicador de la actividad microbiana total.

Los microorganismos y los productos de su metabolismo son los componentes vivientes del suelo y constituyen uno de los parámetros útiles para la medición de su fertilidad. Sin embargo, la medida de la actividad de estos microorganismos es difícil de evaluar debido a la compleja estructura de las comunidades que alberga y sus relaciones, sobre todo en función al ecosistema u otros factores de efecto dominante (Bitton, 1983). Ya que los microorganismos reaccionan fácil y rápidamente a estímulos ambientales, los parámetros de efectos específicos son difíciles de determinar en medio de un gran número de variables influyentes que pueden ser desconocidas o no constantes; es por ello que la variancia en los ensayos es crítica para los procesos de detección de efectos y de interpretación de datos (Burton \& Lanza, 1986). La medición de $\mathrm{CO}_{2}$ producido es una estimación de la actividad y, por lo tanto de la presencia microbiana, tal actividad varía en función de muchos factores, como el uso del suelo, mineralogía, cobertura vegetal, prácticas de manejo, calidad de los residuos que entran al sistema, factores ambientales, entre otros. Según Jenkinson (1992), los factores involucrados en la actividad microbiana, tales como temperatura, $\mathrm{pH}$, humedad, disponibilidad de oxígeno, nutrientes inorgánicos y accesibilidad al sustrato, influyen en la descomposición de la materia orgánica. Así también, ha sido señalado que la actividad y estabilidad de las enzimas en el suelo es regulada por muchos factores como $\mathrm{pH}$ (Frankenberger \& Johanson, 1983; Trasar-Cepeda \& Gil-Sotres, 1987; Dick et al., 1988), biomasa microbiana (Saffigna et al., 1989; Häussling \& Marschner, 1989; Srivastava \& Singh, 1991), vegetación (Juma \& Tabatabai, 1978; Harrison, 1983; Perucci et al., 1984; Helal \& Dressler, 1987; Tarafdar, 1987), prácticas de manejo del suelo y de los cultivos (Perucci \& Scarponi, 1985; Beck, 1990; Martens et al., 1992; Kandeler \& Eder, 1993), materia orgánica del suelo (Juma \& Tabatabai, 1978; Chhonkar \& Tarafdar, 1984; Sparling et al., 1986), minerales de arcilla (Makboul \& Ottow, 1979; Huang et al., 1995) y el contenido de humedad del suelo (Harrison, 1983; West et al., 1988 a,b).

Por todo lo anteriormente mencionado se ha considerado el estudio a nivel de laboratorio de tres variables ambientales conocidas, temperatura, humedad y $\mathrm{pH}$, que influyen en las variaciones de actividad microbiana, estudiándose cada vez los efectos de la variación de una de las variables, en condiciones estándares de los otras dos.

\section{Materiales y métodos}

Las muestras de suelo fueron colectadas del campo experimental El Olivar de la localidad de Pachacamac, Lima y conducidas al Laboratorio de Ecología Microbiana y Biotecnología "Marino Tabusso" de la Universidad Nacional Agraria La Molina, donde se llevó a cabo la realización de los ensayos. Se evaluó la actividad microbiana del suelo en 12 diferentes condiciones experimentales, correspondientes a cuatro distintas temperaturas, cuatro niveles de humedad y cuatro valores de $\mathrm{pH}$ en condiciones estándares de las otras dos cada vez (Tabla 1). Cada prueba de cuatro tratamientos y 4 repeticiones se realizó según el diseño experimental completamente al azar (DCA).

Tabla 1. Tratamientos considerados en la medida de actividad microbiana en suelo a nivel de laboratorio.

\begin{tabular}{cccc}
\hline \multirow{2}{*}{ Tratamiento } & \multicolumn{3}{c}{ Variables evaluadas } \\
\cline { 2 - 4 } & $\begin{array}{c}\text { Humedad } \\
(\mathbf{\%})\end{array}$ & $\begin{array}{c}\text { Temperatura } \\
\left({ }^{\mathbf{0}} \mathbf{C}\right)\end{array}$ & $\mathbf{p H}$ \\
\hline H1 & 5.0 & & \\
H2 & 10.0 & 37.0 & 7.8 \\
H3 & 15.0 & & \\
H4 & 18.0 & 8.0 & \\
\hline T1 & & 21.0 & 7.8 \\
T2 & 18.0 & 27.5 & \\
T3 & & 37.0 & 4.0 \\
T4 & & & 6.1 \\
pH1 & 18.0 & 37.0 & 7.8 \\
pH2 & & & 8.2 \\
pH3 & &
\end{tabular}

Las condiciones mencionadas en la tabla anterior, se alcanzaron al proceder de la manera siguiente: Influencia de la humedad en la actividad microbiana del suelo

El suelo rizosférico exento de materia vegetal fue aireado, tamizado a un tamaño máximo de partícula de $500 \mu \mathrm{m}$ y almacenado herméticamente en frascos de vidrio a temperatura ambiente. Luego de determinarse su humedad inicial se procedió a realizar las correcciones a las humedades de trabajo planificadas (Tabla 1).

Influencia de la temperatura en la actividad microbiana del suelo

El suelo ya tamizado llevado a un porcentaje de humedad gravimétrica del $18 \%$ fue almacenado herméticamente a las temperaturas previstas para la evaluación (Tabla 1).

Influencia del pH en la actividad microbiana del suelo

Se determinó el $\mathrm{pH}$ inicial del suelo tamizado y se llevó a cabo su modificación, adicionando sulfato de cobre para su acidificación y carbonato de calcio para su alcalinización. Luego, se realizó la corrección de su porcentaje de humedad gravimétrica a $18.0 \%$ y se almacenó herméticamente a temperatura ambiente. 
Los tratamientos indicados se realizaron siete días previos a la realización del ensayo, para la adecuación de la microflora a sus nuevas condiciones.

Se determinó la respiración de los microorganismos del suelo, mediante la cuantificación de la producción de $\mathrm{CO}_{2}$ de acuerdo al método descrito por Anderson (1982). La actividad deshidrogenasa en suelos, determinada por reducción de sales tetrazolium de acuerdo al método descrito por Casida (1977) y modificado por Roberge (1978) y recuento de bacterias y de hongos en suelo. Además de manera paralela a los ensayos, se realizaron análisis de humedad gravimétrica y $\mathrm{pH}$ del suelo.

Cuantificación de la producción de dióxido de carbono

Para los ensayos de respiración, cada sistema estuvo conformado por un recipiente plástico de $250 \mathrm{~g}$ de capacidad, con 25 g de suelo tamizado (peso húmedo), al cual se añadió glucosa en solución al 25 \%; luego de mezclar cuidadosamente, se introdujo un pequeño vial conteniendo una solución $\mathrm{NaOH} 1 \mathrm{~N}$, inmediatamente el sistema fue cerrado y sellado. Del mismo modo se instaló un recipiente vacío que sirvió como blanco. Los sistemas de cada tratamiento, junto con el blanco, fueron incubados a $37^{\circ} \mathrm{C}$ por 24 horas. El $\mathrm{CO}_{2}$ producto de la respiración microbiana fue absorbido por la solución de $\mathrm{NaOH}$ con formación de $\mathrm{Na}_{2} \mathrm{CO}_{3}$. El $\mathrm{NaOH}$ remanente o no combinado se valoró con $\mathrm{HCl}$. Cumplido el periodo de incubación, la solución del vial ( $\mathrm{NaOH}$ no combinado), fue titulada en presencia de $\mathrm{BaCl}_{2}$, que precipita el carbonato formado y fenolftaleína.

Los resultados fueron calculados haciendo uso de las siguientes fórmulas:

$\mathrm{V} \mathrm{NaOH}$ convertido en $\mathrm{Na}_{2} \mathrm{CO}_{3}(\mathrm{~mL})=$ gasto $\mathrm{HCl}_{\text {blanco }}(\mathrm{mL})$ - gasto $\mathrm{HCl}_{\text {tratamiento }}(\mathrm{mL})$

$\mathrm{CO}_{2}$ (mg) $=\mathrm{V} \mathrm{NaOH}$ convertido en $\mathrm{Na}_{2} \mathrm{CO}_{3}$ $(\mathrm{mL}) \times$ Normalidad $_{\mathrm{HCl}} \times 22$

Determinación de la actividad deshidrogenasa

En forma paralela, la actividad deshidrogenasa, fue determinada por reducción de sales tetrazolium, su extracción y cuantificación espectrofotométrica de acuerdo al método descrito por Casida (1977) y modificado por Roberge (1978) en la utilización de etanol como extrayente.

Se tomaron $20 \mathrm{~g}$ de suelo tamizado (peso húmedo) que fueron mezclados con $0.2 \mathrm{~g}$ de carbonato de calcio, $\mathrm{CaCO}_{3}$, de esta mezcla se pesaron 2 g en cada uno de 2 frascos estériles color ámbar con cierre hermético que fueron incubados a $28^{\circ} \mathrm{C}$ hasta el análisis.

Para la instalación del ensayo, se añadió solución de extracto de levadura al $0.1 \%$ esterilizada por autoclavado y solución de cloruro de trifenil tetrazolium (TTC) al 3\% esterilizada por filtración a cada uno de los sistemas; excepto para el suelo blanco, al cual se añadió agua destilada estéril en lugar de adicionarle la solución de TTC. Tras el homogeneizado, cerrado de los frascos y sellado con cinta parafilm, se procedió a incubar a $37 \pm 1{ }^{\circ} \mathrm{C}$ por 24 horas. Cumplido el periodo de incubación, se extrajo el trifenil formazán formado como producto de la reducción microbiana. Se añadió etanol absoluto a cada frasco instalado, efectuándose luego una agitación vigorosa y constante, tras lo cual el sobrenadante fue separado del suelo por filtración al vacío y se efectuó la lectura al espectrofotómetro a $485 \mathrm{~nm}$ contra el sobrenadante del blanco. Finalmente, se cuantificó el contenido de la sal reducida mediante una curva de calibración de formazán. Los resultados se expresaron en $\mu \mathrm{g}$ de formazán · (g suelo seco $\cdot 24 \mathrm{~h})^{-1}$

Determinación de las poblaciones microbianas

Para la cuantificación de bacterias y mohos y levaduras de los tratamientos evaluados, se realizaron diluciones sucesivas y se sembraron alícuotas de $1 \mathrm{~mL}$ de cada dilución en medios de agar (agar Plate Count para bacterias y agar Czapeck para hongos). La incubación para los microorganismos aerobios mesófilos viables fue a $30-35{ }^{\circ} \mathrm{C}$ por 48 horas, mientras que, para la enumeración de mohos y levaduras fue a $20-25^{\circ} \mathrm{C}$ por 5 días. Los resultados se expresaron en unidades formadoras de colonias por gramo de suelo seco $\left(\mathrm{UFC} \cdot \mathrm{g}^{-1}\right.$ )

Análisis estadístico

Para cada ensayo, se realizó un análisis de variancia con un nivel de significación del 5\%. Diferencias significativas entre tratamientos fueron evaluadas mediante la prueba de diferencias de pares de medias de Tukey a un nivel de significación del 5\%. Alternativamente se utilizó la Prueba No Paramétrica de Kruskal Wallis con un nivel de confianza del $95 \%$, en caso de no cumplirse con los supuestos del ANOVA.

\section{Resultados}

Influencia de la humedad en la actividad microbiana del suelo

En la Tabla 2 se muestran los valores de la producción de $\mathrm{CO}_{2} \mathrm{y}$ actividad deshidrogenasa a nivel de laboratorio, además, se muestran las poblaciones de microorganismos aerobios mesófilos viables y mohos y levaduras. Los valores promedio de la actividad también se pueden apreciar en la Figura 1.

Las diferencias encontradas fueron altamente significativas entre todos los tratamientos midiendo la actividad microbiana tanto por el método de producción de $\mathrm{CO} 2$, como por el método de actividad deshidrogenasa. Ambos métodos permiten apreciar que un porcentaje de humedad más alto favorece la actividad de los microorganismos en el suelo, al menos en los porcentajes de humedad evaluados. Diferentes autores como Aguilera et al. (1988) y Von Mersi y Schinner (1991) han encontrado que la actividad deshidrogenasa se correlaciona fuertemente con la actividad respiratoria en suelos. 
Tabla 2. Efecto de diferentes porcentajes de humedad en la producción de $\mathrm{CO}_{2}$, actividad deshidrogenasa, población de aerobios mesófilos viables y mohos y levaduras, a nivel de laboratorio.

\begin{tabular}{|c|c|c|c|c|}
\hline \multirow{2}{*}{$\begin{array}{l}\text { ACTIVIDAD } \\
\text { MICROBIANA }\end{array}$} & \multicolumn{4}{|c|}{ HUMEDAD } \\
\hline & $5.0 \%$ & $10.0 \%$ & $15.0 \%$ & $18.0 \%$ \\
\hline $\begin{array}{l}\mathrm{CO}_{2} \\
\left(\mathrm{mg} \mathrm{CO} \cdot \mathrm{g}^{-1} \cdot \mathrm{h}^{-1}\right)\end{array}$ & $\begin{array}{r}0.007 \\
\text { a }\end{array}$ & $0.038^{\mathrm{b}}$ & $0.071^{\mathrm{c}}$ & $0.097^{\mathrm{d}}$ \\
\hline $\begin{array}{l}\text { DHA } \\
\left(\mu g \text { formazán } \cdot g^{-1} \cdot(24 h)^{-1}\right)\end{array}$ & $\begin{array}{r}116.0 \\
0^{\mathrm{a}}\end{array}$ & $131.96^{\mathrm{b}}$ & $153.16^{\mathrm{c}}$ & $173.09^{d}$ \\
\hline $\begin{array}{l}\text { Aerobios mesófilos } \\
\text { viables } \\
\left(\mathrm{Ln}\left(\mathrm{UFC} \cdot \mathrm{g}^{-1}\right)\right)\end{array}$ & 16.03 & 16.11 & 17.42 & 17.89 \\
\hline $\begin{array}{l}\text { Mohos y levaduras } \\
\left(\operatorname{Ln}\left(\mathrm{UFC} \cdot \mathrm{g}^{-1}\right)\right)\end{array}$ & 10.91 & 11.09 & 11.08 & 11.20 \\
\hline
\end{tabular}
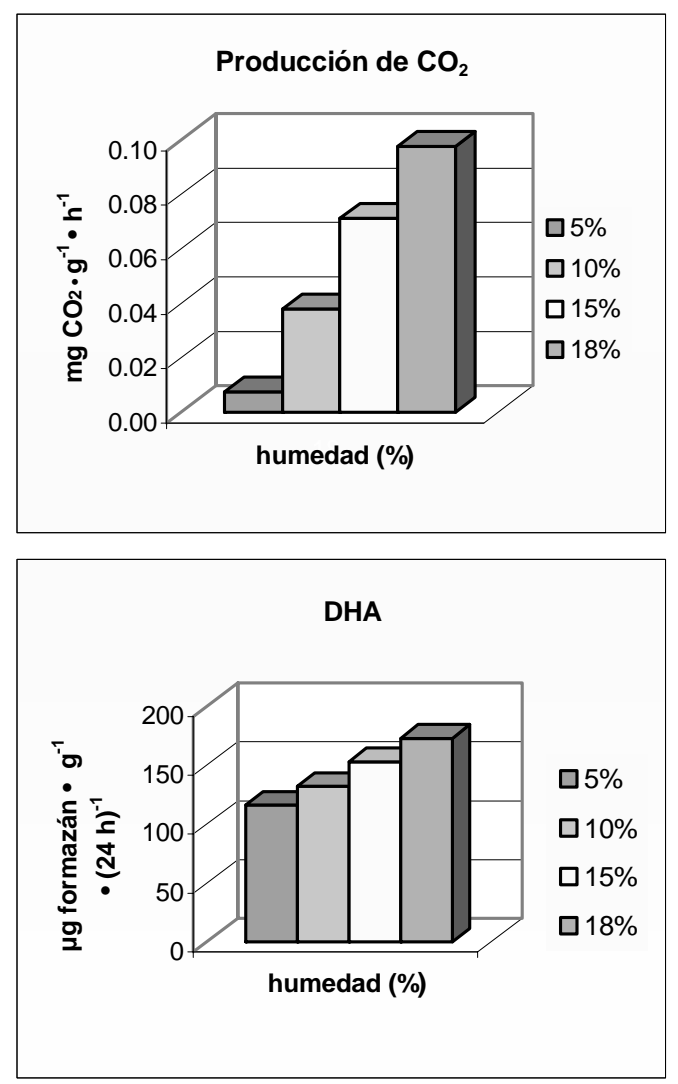

Figura 1. Efecto de diferentes porcentajes de humedad en la producción de CO2 y actividad deshidrogenasa (DHA) a nivel de laboratorio.

La tasa más alta de respiración y la de actividad deshidrogenasa ocurrió a un porcentaje de humedad del $18.0 \%$. Valores más altos de humedad no fueron evaluados debido a la saturación del suelo ensayado. Lo encontrado es consistente con lo reportado en la literatura: un incremento en el agua del suelo reduce el estado de aireación por reducción del espacio de los poros llenos de aire disponibles para la difusión de gases (Brzezinska et al., 1998) y la actividad deshidrogenasa es mayor en suelos inundados que en suelos no inundados. Okazaki et al. (1983) y Pedrazzini \& Mckee (1984) encontraron que el incremento de la actividad deshidrogenasa luego de la inundación está acompañado por el decrecimiento del potencial redox. Glinski et al. $(1983,1986)$ midieron la actividad enzimática de suelos tanto bajo condiciones de campo como de laboratorio; ellos mostraron en los horizontes de humus de 2 suelos, una tendencia de la actividad deshidrogenasa a incrementarse bajo condiciones hipóxicas inducidas por alto contenido de agua. Para lograr este efecto, Brzezinska et al. (1998) recomiendan dejar una pequeña cantidad de líquido libre en la superficie del suelo a evaluar.

Por otro lado, se puede evidenciar de manera clara que a porcentajes de humedad bajos, la actividad microbiana es menor. En este sentido, se ha reportado que la actividad microbiana, medida por el $\mathrm{CO}_{2}$ desprendido, está fuertemente influenciada por el potencial hídrico. Suelos desecados hasta un potencial hídrico de -10 MPa liberan $\mathrm{CO}_{2}$ con una velocidad del orden del $50 \%$ de la observada si los suelos son incubados con un contenido óptimo de humedad, normalmente con un potencial hídrico comprendido entre -20 y $-50 \mathrm{kPa}$. Cuando el potencial hídrico alcanza valores muy negativos, la actividad microbiana cesa (Jenkinson, 1992). Por otro lado, estudios de Ross (1970), demostraron que el solo secado al aire de muestras de suelo, reduce la actividad deshidrogenasa a la mitad.

En los recuentos de microorganismos aerobios mesófilos viables y mohos y levaduras, puede distinguirse una pequeña tendencia al aumento conforme se incrementa el porcentaje de humedad en las muestras de suelo. Así podemos apreciar que el Ln (UFC $\cdot \mathrm{g}^{-1}$ ) de bacterias asciende de 16.03 a 17.89 para porcentajes de humedad del suelo de $5.0 \%$ y $18.0 \%$ respectivamente, en tanto que el $\mathrm{Ln}\left(\mathrm{UFC} \cdot \mathrm{g}^{-1}\right.$ ) de hongos se incrementa de 10.91 a 11.20 para los mismos porcentajes de humedad.

Influencia de la temperatura en la actividad microbiana del suelo

La producción de $\mathrm{CO}_{2}$ y actividad deshidrogenasa, así como las poblaciones de bacterias y hongos determinadas en suelo a diferentes temperaturas a nivel de laboratorio, son mostradas en la Tabla 3 y Figura 2. 
Tabla 3. Efecto de diferentes temperaturas en la producción de $\mathrm{CO}_{2}$, actividad deshidrogenasa, microorganismos aerobios mesófilos viables y mohos y levaduras a nivel de laboratorio.

\begin{tabular}{|c|c|c|c|c|}
\hline \multirow{2}{*}{$\begin{array}{l}\text { ACTIVIDAD } \\
\text { MICROBIANA }\end{array}$} & \multicolumn{4}{|c|}{ TEMPERATURA $\left({ }^{\circ} \mathrm{C}\right)$} \\
\hline & 8.0 & 21.0 & 27.5 & 37.0 \\
\hline $\begin{array}{l}\mathrm{CO}_{2} \\
(\mathrm{mg} \mathrm{CO} \\
\left.\mathrm{CO}_{2} \cdot \mathrm{g}^{-1} \cdot \mathrm{h}^{-1}\right)\end{array}$ & 0.021 & 0.066 & 0.140 & 0.128 \\
\hline $\begin{array}{l}\text { DHA } \\
(\mu \mathrm{g} \text { formazán } \cdot \\
\left.\mathrm{g}^{-1} \cdot(24 \mathrm{~h})^{-1}\right)\end{array}$ & $0.169^{\mathrm{a}}$ & $48.13^{b}$ & $80.79^{c}$ & $156.78^{d}$ \\
\hline $\begin{array}{l}\text { Aerobios } \\
\text { mesófilos } \\
\text { viables } \\
\left(\mathrm{Ln}\left(\mathrm{UFC} \cdot \mathrm{g}^{-1}\right)\right)\end{array}$ & 16.03 & 16.11 & 17.42 & 17.89 \\
\hline $\begin{array}{l}\text { Mohos } \\
\text { levaduras } \\
\left(\operatorname{Ln}\left(\mathrm{UFC} \cdot \mathrm{g}^{-1}\right)\right)\end{array}$ & 10.91 & 11.09 & 11.08 & 11.20 \\
\hline $\begin{array}{l}\mathrm{a}, \mathrm{b}, \mathrm{d}, \mathrm{E} \text { cada fil } \\
\text { indican la existe } \\
\text { a la prueba de } \\
(\mathrm{P}=0.05) \text {. }\end{array}$ & $\begin{array}{l}\text { atami } \\
\text { a de d } \\
\text { aparac }\end{array}$ & $\begin{array}{l}\text { segui } \\
\text { ncias } \\
\text { múlt }\end{array}$ & por dif & $\begin{array}{l}\text { ntes letras } \\
\text { le acuerdo } \\
\text { kal Wallis }\end{array}$ \\
\hline
\end{tabular}
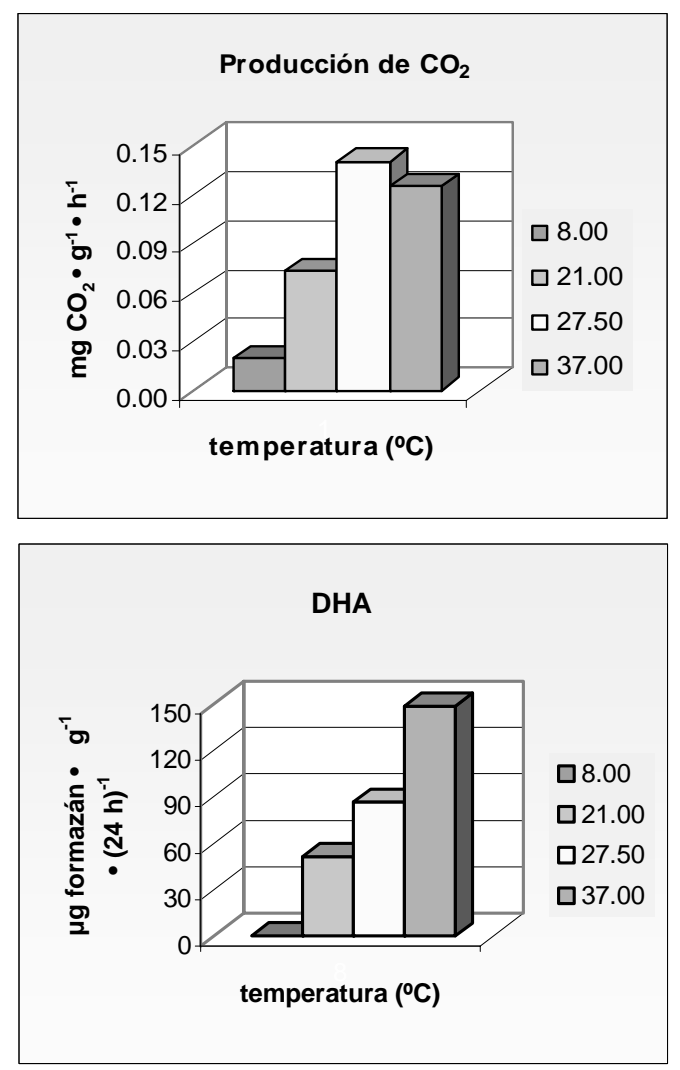

Figura 2. Efecto de diferentes temperaturas en la producción de $\mathrm{CO} 2$ y actividad deshidrogenasa a nivel de laboratorio.

De acuerdo al análisis estadístico no paramétrico realizado, prueba de Kruskal Wallis, no existieron diferencias significativas entre tratamientos para la medida de la producción de $\mathrm{CO}_{2}(\mathrm{p}>0.05)$. Sin embargo, en pruebas de respiración con glucosa como medida del efecto de las temperaturas en la actividad microbiana total de turbas, Qureshi et al. (2003) encontraron que la tasa más alta de respiración acumulativa ocurrió a $28{ }^{\circ} \mathrm{C}$ y decreció conforme la temperatura decrece $\left(16{ }^{\circ} \mathrm{C}\right.$ y $\left.4{ }^{\circ} \mathrm{C}\right)$, consistente con la tendencia de los resultados encontrados en este trabajo, pues tasas de respiración en orden decreciente fueron observadas a $27.5{ }^{\circ} \mathrm{C}>21.0{ }^{\circ} \mathrm{C}>8.0{ }^{\circ} \mathrm{C}$. Qureshi et al. (2003) reportaron también que la respiración microbiana más baja en las mismas turbas evaluadas, ocurrió a $37.0^{\circ} \mathrm{C}$, sin embargo, en este trabajo, la tasa de respiración encontrada a $37.0{ }^{\circ} \mathrm{C}$ si bien, presenta una tendencia menor a la obtenida a $27.5^{\circ} \mathrm{C}$, es superior a las temperaturas de $21.0^{\circ} \mathrm{C} \mathrm{y}$ $8.0^{\circ} \mathrm{C}$.

En cuanto a la actividad deshidrogenasa, sí se detectaron diferencias altamente significativas entre los tratamientos a diferentes temperaturas, los resultados son mostrados en la Tabla 3.

La bibliografía reporta que la actividad microbiana es baja en muestras sometidas a bajas temperaturas, así, Burton (1986) reportó la pérdida de actividad deshidrogenasa en sedimentos almacenados a $4{ }^{\circ} \mathrm{C}$ o congelados.

Por otro lado, Brzezinska et al. (1998) observaron que la actividad deshidrogenasa incrementaba especialmente con el tratamiento de saturación con agua, haciéndose este tratamiento más diferenciado a altas temperaturas. Ellos obtuvieron valores máximos de actividad a $30{ }^{\circ} \mathrm{C}$, valores mayores en más de 10 veces que los obtenidos a $20^{\circ} \mathrm{C}$ y $10{ }^{\circ} \mathrm{C}$; en sus pruebas, aumentos de temperatura de 10 a $20^{\circ} \mathrm{C}$ y de 20 a $30{ }^{\circ} \mathrm{C}$ causaron incrementos en la actividad deshidrogenasa en factores de 3.2 y 3.9 respectivamente, factores calculados como valores promedio de todos los tratamientos con agua. Además efectuaron ensayos en los que los valores de coeficiente de temperatura para suelos bajo condiciones aireadas (tensión de agua en el suelo de $15.9 \mathrm{kPa}$ ) fueron solo de 2.6, pero fueron de 4.6 en el caso de suelos totalmente saturados con agua.

En este trabajo se demuestra que al incrementar la temperatura de 8.0 a $21.0{ }^{\circ} \mathrm{C}$, la actividad deshidrogenasa aumenta considerablemente en un factor de 284.79 (Tabla 3, Figura 2); de 21.0 a $27.5^{\circ} \mathrm{C}$ aumenta en un factor de 1.68; mientras que al incrementarse de 27.5 a $37.0{ }^{\circ} \mathrm{C}$, el aumento de la actividad se da en un factor de 1.94. Estudios de Casida et al. (1964), mostraron que una reducción no biológica del TTC podría ocurrir a temperaturas superiores a esta. Para los mismos incrementos de temperatura (8.0 a $21.0{ }^{\circ} \mathrm{C}$ y 21.0 a $27.5^{\circ} \mathrm{C}$ ) en los ensayos realizados para este trabajo, la tasa de producción de CO2 aumentó en 3.14 y 2.12 respectivamente y disminuyó en 0.91 al efectuar un incremento en la temperatura de 27.5 a $37^{\circ} \mathrm{C}$. 
Influencia del pH en la actividad microbiana del suelo

La influencia del $\mathrm{pH}$ en la actividad microbiana (producción de $\mathrm{CO}_{2}$ y actividad deshidrogenasa) y en las poblaciones de microorganismos aerobios mesófilos viables y mohos y levaduras se muestran a continuación (Tabla 4 y Figura 3).

No existió diferencias significativas entre tratamientos para la medida de la producción de $\mathrm{CO}_{2}$ ( $>0.05)$ mediante el análisis de variancia no paramétrico realizado (prueba de Kruskal Wallis). Sin embargo, sí se observaron diferencias significativas y altamente significativas entre tratamientos para la medida de la actividad deshidrogenasa $(\mathrm{p}<0.05)$.

Tabla 4. Efecto de diferentes valores de $\mathrm{pH}$ del suelo en la producción de $\mathrm{CO}_{2}$, actividad deshidrogenasa, población de aerobios mesófilos viables y mohos $\mathrm{y}$ levaduras, a nivel de laboratorio.

\begin{tabular}{|c|c|c|c|c|}
\hline \multirow{2}{*}{$\begin{array}{l}\text { ACTIVIDAD } \\
\text { MICROBIANA }\end{array}$} & \multicolumn{4}{|c|}{$\mathrm{pH}$} \\
\hline & 4.0 & 6.1 & 7.8 & 8.2 \\
\hline $\begin{array}{l}\mathrm{CO}_{2} \\
\left(\mathrm{mg} \mathrm{CO}_{2} \cdot \mathrm{g}^{-1} \cdot \mathrm{h}^{-1}\right)\end{array}$ & $0.048^{\mathrm{a}}$ & $0.052^{\mathrm{a}}$ & $0.055^{\mathrm{a}}$ & $0.054^{\mathrm{a}}$ \\
\hline $\begin{array}{l}\text { DHA } \\
\left(\mu \mathrm{g} \text { formazán } \mathrm{g}^{-1} \cdot 24 \mathrm{~h}^{-1}\right) \\
\text { Aerobios mesófilos } \\
\text { viables }\end{array}$ & $8.10^{\mathrm{a}}$ & $45.31^{b}$ & $171.19^{d}$ & $106.40^{c}$ \\
\hline$\left(\operatorname{Ln}\left(\mathrm{UFC} \cdot \mathrm{g}^{-1}\right)\right)$ & 13.51 & 14.78 & 14.78 & 13.71 \\
\hline $\begin{array}{l}\text { Mohos y levaduras } \\
\left(\operatorname{Ln}\left(\mathrm{UFC}^{-} \cdot \mathrm{g}^{-1}\right)\right)\end{array}$ & 10.87 & 11.12 & 10.90 & 10.62 \\
\hline
\end{tabular}

Los resultados obtenidos mediante la prueba de actividad deshidrogenasa resultan consistentes con lo hallado por otros autores, Alef (1995) sobre la base de resultados no publicados, puntualizó que los suelos ácidos $(\mathrm{pH}<5)$ tienden a mostrar actividades deshidrogenasas muy bajas que deberían ser interpretadas con cuidado, pues el TTC puede ser adsorbido por coloides orgánicos e inorgánicos. Del ensayo realizado, se puede afirmar que el pH influyó sobre la actividad de las deshidrogenasas, aumentando éstas a medida que el mismo se acercaba a la neutralidad, algo que también está de acuerdo con los resultados obtenidos en los recuentos de bacterias y de hongos, aunque los tratamientos no muestren diferencias significativas entre ellos. Así, la mayor producción de formazán se dio a pH 7.8, descendiendo significativamente si la actividad es medida a pH 8.2. Así también, Dick \& Tabatabai (1993) mencionan que, el $\mathrm{pH}$ del suelo solo tiene influencia sobre las enzimas hidrolasas y no sobre las oxidorreductasas, de las cuales las deshidrogenasas forman parte.
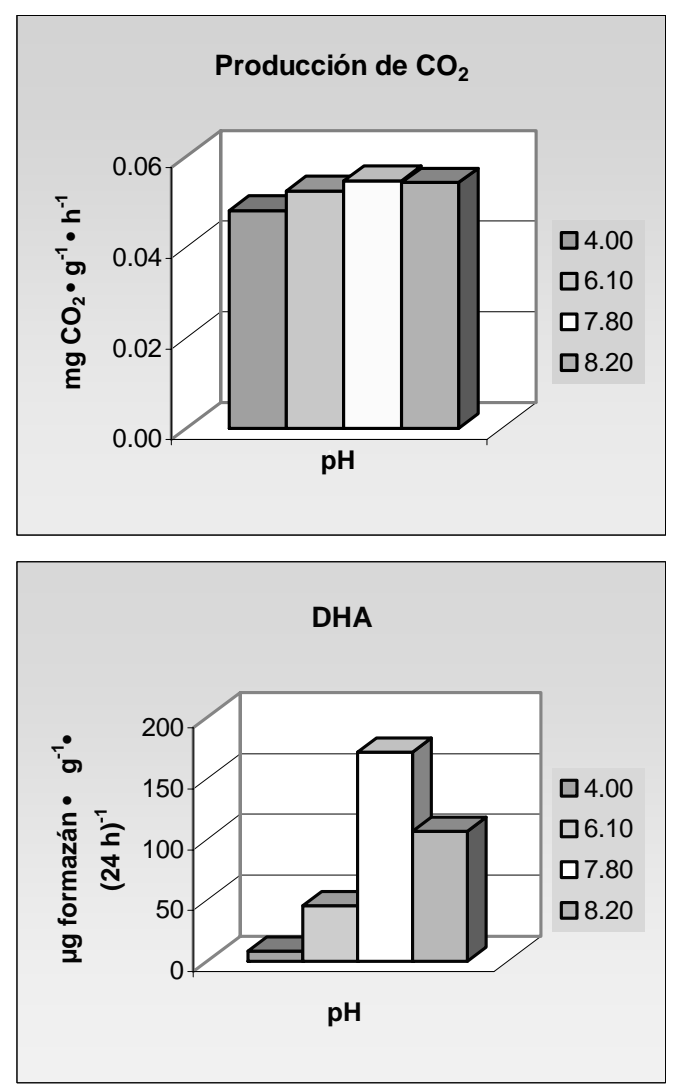

Figura 3. Efecto de diferentes valores de $\mathrm{pH}$ del suelo en la producción de $\mathrm{CO}_{2}$ y actividad deshidrogenasa a nivel de laboratorio.

Como con todas las pruebas con enzimas, las condiciones de incubación determinan la tasa de catálisis del sustrato, por ello, el diseño de las mediciones de enzimas del suelo y la interpretación de la información resultante son controversiales. Así, el uso de tampones es fuertemente debatido (Gianfreda \& Bollag, 1996). Los tampones son usados principalmente para equilibrar y mantener el $\mathrm{pH}$ en el óptimo para la actividad (Kandeler \& Gerber, 1988), con lo cual se provee una medida del potencial enzimático. Una segunda apreciación es el confiar en la capacidad tamponante inherente al propio suelo usando agua purificada (Gong, 1997) o usar tampones únicamente para mantener el $\mathrm{pH}$ en la masa de suelo (Sinsabaugh et al., 2000), en estas condiciones se puede estar midiendo la actividad a un $\mathrm{pH}$ sub óptimo, produciendo una tasa menor de catálisis de sustrato, pero que es más parecido al mostrado en el ambiente natural. De manera alternativa, las mediciones de actividad enzimática al pH natural del suelo pueden dar una indicación más real de la actividad, semejante a la expresada in situ (Kandeler \& Gerber, 1988). Y para efectos de la presente investigación, es esta última consideración la tomada en cuenta. 


\section{Conclusiones}

1. La actividad microbiana mejora significativamente con el incremento de la humedad. Se encontró la mayor tasa de producción de $\mathrm{CO}_{2}$ y actividad deshidrogenasa a un porcentaje de humedad de $18.0 \%$ en suelo [0.097 mg $\mathrm{CO}_{2} \cdot \mathrm{g}^{-1} \cdot \mathrm{h}^{-1}$ y $173.09 \mu \mathrm{g}$ formazán.g$\left.{ }^{1} \cdot(24 \mathrm{~h})^{-1}\right]$.

2. La temperatura afecta significativamente la actividad microbiana del suelo; encontrándose que la temperatura de $27.5^{\circ} \mathrm{C}$ fue óptima para la producción de $\mathrm{CO}_{2}\left[0.140 \mathrm{mg} \mathrm{CO} \cdot \mathrm{g}^{-1} \cdot \mathrm{h}^{-1}\right.$ ] y 37.0 ${ }^{\circ} \mathrm{C}$ para la actividad deshidrogenasa [156.78 $\mu \mathrm{g}$ formazán $\left.\cdot g^{-1} \cdot(24 h)^{-1}\right]$.

3. El pH del suelo también resultó ser un factor limitante para la actividad microbiana. A pH 7.8 se registró la mayor actividad deshidrogenasa [171.19 $\mu \mathrm{g}$ formazán $\left.\cdot \mathrm{g}^{-1} \cdot(24 \mathrm{~h})^{-1}\right]$, descendiendo significativamente a valores de $\mathrm{pH}$ 4.0, 6.1 y 8.2.

\section{Agradecimientos}

Agradecemos al CONCYTEC - PROCYT 207 2005 y al Laboratorio de Ecología Microbiana y Biotecnología "Marino Tabusso"- UNALM (Subcuenta Biología 111 de la Fundación para el Desarrollo Agrario). Al Programa de Leguminosas de la Facultad de Agronomía de la UNALM y al profesor Mg. Sc. Abelardo Calderón del Laboratorio de Fisiología Vegetal por las facilidades prestadas.

\section{Literatura citada}

Aguilera M., Borie G., Rokov P. \& Peirano P. 1988. Bioquímica de suelos derivados de cenizas volcánicas. VIII. Determinación de deshidrogenasas. Agricultura Técnica (Chile). 48: 147-151.

Alef K. 1995. Estimation of microbial activities. Págs: 193-270. En: K. Alef y P. Nannipieri (eds). Methods in Applied Soil Microbiology and Biochemistry. Academic Press. Londres.

Anderson J. 1982. Soil Respiration. Págs : 831-871. En: Page A., Miller R. y Kenney D. (eds). Methods of soil analysis. Part II. Chemical and microbiological properties. 2nd ed. American Society of Agronomy. Number 9. Madison, Wisconsin, USA.

Beck T. 1990. Der Einfluß langjähriger Bewirtschaftungsweise auf bodenmikrobiologische Eigenschaften. Kali-Briefe. 20(1): 17-29.

Bitton G. 1983. Bacterial and biochemical tests for assessing chemical toxicity in the aquatic environment: a review. CRC Critical Rev. Environmental Control. 13 (1): 5167.

Brzezinska M., Stepniewska Z. \& Stepniewski W. 1998. Soil oxygen status and dehydrogenase activity. Soil Biol. Biochem. 30(13): 1783-1790.

Burton W. 1986. The Potato. Ed 3. Longman Scientific and Technical, Harlow, UK.

Burton G. \& Lanza G. 1986. Variables affecting to electron transport system assays. Applied and Environmental Microbiology. 51(5): 931-937.
Casida L. 1977. Microbial metabolic activity in soil as measured by dehydrogenase determinations. Applied and Environmental Microbiology. 34(6): 630-636.

Casida L., Klein D. \& Santoro T. 1964. Soil dehydrogenase activity. Soil Sci. 98: 371-376.

Chhonkar P. \& Tarafdar J. 1984. Accumulation of phosphatases in soils. J Indian Soc Soil Sci. 32: 266272.

Dick R., Rasmussen P. \& Kerle E. 1988. Influence of longterm residue management on soil enzyme activities in relation to soil chemical properties of a wheatfallow system. Biol Fertil Soils. 6: 159-164.

Dick W. \& Tabatabai M. 1993. Significance and potential uses of soil enzymes. Págs: 95-127. En: Blaine F. (ed). Soil microbial ecology: applications in agricultural and environmental management. Marcel Dekker, New York.

Frankenberger T. \& Johanson J. 1983. Factors affecting invertase activity in soils. Plant and Soil. 74: 313-323.

Gianfreda L. \& Bollag J. 1996. Influence of natural and anthropogenic factors on enzyme activity in soil. Págs: 123-193. In: Stotzky G. \& Bollag J. (eds.). Soil Biochemistry, Vol. 9. Marcel Dekker, New York.

Glinski J., Stepniewska Z. \& Kasiak A. 1983. Changes of soil enzyme activity under different conditions of oxygen content and moisture (in Polish). Roczn Glebozn. 34: 53-59.

Glinski J., Stepniewska Z. \& Brzezinska M. 1986. Characterization of dehydrogenase and catalase activity of the soils of the two natural sites with respect to the soil oxygenation status. Polish J. Soil Sci. 19: 47-52.

Gong P. 1997. Dehydrogenase activity in soil: a comparison between the TTC and INT assay under their optimum conditions. Soil Biology \& Biochemistry. 29: 211-214.

Harrison A. 1983. Relatioship between intensity of phosphatase activity and physico - chemical properties in woodland soils. Soil Biol Biochem.15: 93-99.

Häussling M. \& Marschner H. 1989. Organic and inorganic soil phosphates and acid phosphates activity in the rhizosphere of 80-year-old Norway spruce (Picea abies (L.) Karst.) trees. Biol. Fertil. Soils. 8: 128-133.

Helal H. \& Dressler A. 1987. Mobilization and turnover of soil phosphorus in the rhizosphere. A Pflanzenernär Bodenk. 152:175-180.

Huang Q., Skindo H. \& Goh T. 1995. Adsorption, activities and kinetics of acid phosphatase as influenced by montmorillonite with different interlayer material. Soil Sci. 159(4): 27-278.

Jenkinson D. 1992. La Materia Orgánica del Suelo: Evolución. En: Wild A. Condiciones del suelo y desarrollo de las plantas. Madrid. Mundi-Prensa.

Juma N. \& Tabatabai M. 1978. Distribution of phosphomonoesterases in soil. Science. 126 (2): 101-108.

Kandeler E. \& Eder G. 1993. Effect of cattle slurry in grassland on microbial biomass and on activities of various enzymes. Biol Fertil Soils. 16: 249-254.

Kandeler E. \& Gerber H. 1988. Short-term assay of soil urease activity using colorimetric determination of ammonium. Biology and Fertility of Soils. 6: 68-72.

Makboul H. \& Ottow J. 1979. Alkaline phosphatase activity and Michaelis constant in the presence of different clay minerals. Soil Sci. 128 (3): 129-135.

Martens D., Johanson J. \& Frankenberger W. 1992. Production and persistence of soil enzymes with 
repeated addition of organic residues. Soil Sci. 153 (1): 53-61.

Okazaki M., Hirata E. \& Tensho K. 1983. TTC reduction in submerged soils. Soil Science and Plant Nutrition. 29: 489-497.

Pedrazzini F. \& McKee K. 1984. Effect of flooding on activities of soil dehydrogenases in rice (Oryza sativa L.) roots. Soil Science and Plant Nutrition. 30: 359-366.

Perucci P. \& Scarponi L. 1985. Effect of different treatments with crop residues on soil phosphatase activity. Biol Fertil Soils. 1: 111-115.

Perucci P., Scarponi L. \& Businelli M. 1984. Enzyme activities in a clay-loam soil amended with various crop residues. Plant Soil. 81: 345-351.

Qureshi S., Richards B., Hay A., Tsai C., McBride M., Baveye P. \& Steenhuis T. 2003. Effect of microbial activity on trace element release from sewage sludge. Environ. Sci. Technol. 37: 3361-3366.

Roberge M. 1978. Methodology of soil enzyme measurement and extraction: catalase. Pág: 344. In: Burns R. (ed) Soil Enzymes. Academic Press, London.

Ross D. 1970. Effects of storage on dehydrogenase activities of soils. Soil Biology \& Biochemistry. 2: 5561.

Saffigna P., Powlson D., Brookes P. \& Thomas G. 1989. Influence of sorghum residues and tillage on soil organic matter and soil microbial biomass in an Australian vertisol. Soil Biol. Biochem. 21: 759-765.

Sinsabaugh R., Reynolds H. \& Long, T. 2000. Rapid assay for amidohydrolase (urease) activity in environmental samples. Soil Biol. Biochem. 32: 2095-2097.
Skujins J. 1976. Extracellular enzymes in soil. Crit. Rev. Microbiol. 4: 383-421.

Sparling G., Speir T. \& Whale K. 1986. Changes in microbial biomass C, ATP content, soil phosphomonoesterase and phosphodiesterase activity following air-drying of soils. Soil Biol Biochem. 18 (4): 363-370.

Srivastava S. \& Singh J. 1991. Microbial C, N and P in dry tropical forest soils: effects of alternate land-uses and nutrient flux. Soil. Biol. Biochem. 23:117-124.

Tarafdar J. 1987 Activity of enzymes added to soils. Polish. Journal of Soil Science. 20:5-10.

Trasar-Cepeda M. \& Gil-Sotres F. 1987. Phosphatase activity in acid high organic matter soils in Galicia (NW Spain). Soil Biol. Biochem. 19: 281-287.

Von Mersi W. \& Schinner F. 1991. An improved and accurate method for determining the dehydrogenase activity of soils with iodonitrotetrazolium chloride. Biology and Fertility of Soils. 11: 216-220.

West A., Sparling G., Speir T. \& Wood J. 1988a. Comparison of microbial $\mathrm{C}, \mathrm{N}$-flush and ATP, and certain enzyme activities of different textured soils subject to gradual drying. Aust J Soil Res. 26: 217-229.

West A., Sparling G., Speir T. \& Wood J. 1988b. Dynamics of microbial C, N-flush and ATP, and enzyme activities of gradually dried soils from a climosequence. Aust J Soil Res. 26: 519-530.

${ }^{1}$ Laboratorio de Ecología Microbiana y Biotecnología Marino Tabusso. Universidad Nacional Agraria La Molina. 2005. Av. La Molina s/n. Lima 12 - Perú. dzuniga@lamolina.edu.pe 